\title{
Impact of a complex gender-transformative intervention on maternal and child health outcomes in the eastern Democratic Republic of Congo: protocol of a longitudinal parallel mixed-methods study
}

Wyvine Ansima Bapolisi ${ }^{1,2,3}$, Giovanfrancesco Ferrari ${ }^{1,2}$, Clara Blampain ${ }^{1,2}$, Jean Makelele ${ }^{4}$, Lenneke Kono-Tange ${ }^{5}$, Ghislain Bisimwa ${ }^{3}$ and Sonja Merten ${ }^{1,2^{*}}$ (D)

\begin{abstract}
Background: In the eastern part of the Democratic Republic of Congo (DRC) Village Savings and Loan Associations (VSLAs) programs targeting women are implemented. In the context of the 'Mawe Tatu' program more equitable intra-household decision-making is stipulated by accompanying women's participation in VSLAs with efforts to engage men for more gender equality, expecting a positive effect of this combined intervention on the household economy, on child nutritional status, on the use of reproductive health services including family planning, and on reducing sexual and gender-based violence (SGBV).

Methods: A longitudinal parallel mixed method study is conducted among women participating in VSLAs in randomly selected project areas and among a control group matched for socioeconomic characteristics. Descriptive statistics will be calculated and differences between intervention and control groups will be assessed by Chi2 tests for different degrees of freedom for categorical data or by t-tests for continuous data. Structural equation modelling (SEM) will be conducted to investigate the complex and multidimensional pathways that will affect household economic status, child nutritional status and use of reproductive health services. Analysis will be conducted with STATA V.15.

Concomitantly, qualitative data collection will shed light on the intra-household processes related to gender powerrelations that may be linked to women's participation in economic activities and may lead to improvements of maternal and child health. Focus group discussions and in-depth interviews will be conducted. All narrative data will be coded (open coding) with the help of qualitative data analysis software (Atlas TI).

Discussion: Women's empowerment has long been identified as being able to bring about progress in various areas, including health. It has been shown that men's commitment to transforming gender norms is a sinequanone factor for greater equity and better health, especially in terms of reproductive health and child nutrition. This study is one of the first in this genre in DRC and results will serve as a guide for policies aimed at improving the involvement of men in changing attitudes towards gender norms for higher household productivity and better health.
\end{abstract}

Keywords: Women's empowerment, Decision-making, Gender equality, Male involvement, SGBV, Child nutritional status, Reproductive health, Family planning

\footnotetext{
* Correspondence: sonja.merten@swisstph.ch

'Swiss Tropical and Public Health Institute, Basel, Switzerland

University of Basel, Basel, Switzerland

Full list of author information is available at the end of the article
}

C The Author(s). 2020 Open Access This article is distributed under the terms of the Creative Commons Attribution 4.0 International License (http://creativecommons.org/licenses/by/4.0/), which permits unrestricted use, distribution, and reproduction in any medium, provided you give appropriate credit to the original author(s) and the source, provide a link to the Creative Commons license, and indicate if changes were made. The Creative Commons Public Domain Dedication waiver (http://creativecommons.org/publicdomain/zero/1.0/) applies to the data made available in this article, unless otherwise stated. 


\section{Background}

Maternal and child health are among the most important indicators of a country's development. Major causes of maternal mortality can be prevented and treated with simple, affordable health interventions such as antenatal care (ANC) or vaccination if used adequately and on time [1]. Children's nutritional status is a sensitive indicator for household poverty, with childhood malnutrition having many long-term effects for health [2-4]. The Democratic Republic of the Congo (DRC) is among the poorest countries in the world and heavily indebted with high rates of maternal and child mortality [5]. The country was ranked as the 176th of 188 countries in terms of human development index [5]. In 2015 maternal mortality was estimated at 693 per 100,000 and the under-five mortality rate was around 308 per 1000 [6]. Malnutrition is rampant where $43 \%$ of children under five are malnourished and around $76 \%$ of women encounter barriers accessing maternal health care services [7]. The country has been involved in repetitive wars for over 20 years, and the East of the country is still facing rebellions. Insecurity prevails and unemployment is widespread. Like in many other countries, women ensure much of the economic activities of a household, and largely carry the responsibility for providing and caring for household members; men endorse the role of decision-making for all expenditures including health [8-10]. This is confirmed according to the Demographic and Health Survey $2014 / 15$, where only $29 \%$ women decided themselves how to use the money they have earned. When it comes to decision making about their own health only $36 \%$ of the women decided themselves [7]. As women are usually the main caregivers of children, women's limited decision-making negatively affects their children's health and wellbeing [11-14]. Men's involvement remains important though. A lack of participation of men in programs improving sexual and reproductive health has also been revealed as one of the reasons for poor progress observed in the domain of family planning and persisting disagreement between spouses regarding their choice for sexual and reproductive health service use [15-18]. Studies showed that male involvement led to better results regarding the use of contraceptives [18-20]. Barker and others have further demonstrated that the involvement of men in family health can be a mediator towards better health [21-24].

Women's empowerment is a process of awareness and capacity building leading to greater participation, to greater decision-making power, and to transformative action in different domains such as rights, health, or economics [8, 25]. In the literature, economic empowerment was presented as a key factor for better health and to palliate all types of violence including intimate partner violence [26-28]. However, in a male-dominated society, women's economic empowerment is not the sole factor to fight partner violence and can lead to resistance due to restrictive gender norms. Therefore, actions engaging men to support women's empowerment must be part of interventions that aim at strengthening women's economic participation [29-31] .

It has been shown that sufficient resources and an enabling environment allows women to make decisions about their own health, which leads to improved health outcomes specifically as regards sexual and reproductive health (SRH) [32-35]. Yet, in South Kivu and in other African contexts women often lack access to health services and also the financial resources to meet every day needs $[9,36]$. As both are required, improvement of cash income, and a more equitable decision-making about the use of resources at the level of the household, complex interventions combining those two aspects are needed.

One of the most widely implemented approaches to improve population health is the introduction of microfinance including projects containing a social development component such as Village Savings and Loans Associations (VSLA) [37-40]. A VSLA is a platform for developing women's capacities in organizational and financial matters, to improve self-efficacy and decision-making, and other skills. This approach was receiving increasing attention in the 1990 s as a community-managed microfinance approach with a social mobilization component [41]. A VSLA is a self-selected group of 25 to 30 persons who agree to save a certain amount defined by all the members every week. Members self-organize in a committee with a president and meet every week. Loans can be taken up to 3 times the savings a member has contributed, and the loan has to be paid back with an interest rate of 5-10\% according to what the group has defined. A normal cycle of a VSLA is nine to 12 months, after that a new VSLA has to be set up.

Several studies evaluated VSLA programs showing positive effects on general welfare and on child wellbeing $[37,39,42]$. Positive impacts on health were stronger if VSLA programs were in conjuncture with health education [21, 35, 43]. There is some evidence on the effectiveness of VSLAs in fragile contexts, which focused on specific subgroups. A study in post-conflict Ivory Coast showed positive effects of an intervention focusing on gender relations in combination with VSLAs on household economies and gender equity [29]. In Eastern DRC, a project evaluation among female sexual violence survivors showed a positive effect of a VSLA program on food consumption and stigma reduction [44]. A limitation of the approach is however the self-selection process when forming VSLA groups, which can lead to the exclusion of socially marginalized persons if they are not explicitly targeted $[41,45]$.

To improve gender equity within households, several approaches towards engaging men for gender equity have been developed, a prominent example being the Promundo 
approach, which is based on men-to-men sensitization developing 'positive masculinity'. Men engage men towards more equitable gender norms to adopt attitudes and behaviour promoting women's economic empowerment and helping to reduce gender based violence; "Positive masculinity" refers to positive changes in attitudes and behaviours transforming the socio-cultural norms associated with masculinity $[46,47]$. Once men are sensitized to the benefits of women's empowerment, they could become active advocates for women's and children's welfare in the household as well as in the community and change gender-based inequities in health [38].

Increasingly, projects target women and men jointly in order to transform gender-inequitable norms and behaviors, yielding encouraging results for example on reducing gender based violence [30, 48, 49]. Projects engaging men can be part of complex interventions, but only a few have combined these approaches with VSLAs [29,31].

\section{Mawe tatu program}

The "Mawe tatu" program, implemented in the Eastern part of the Democratic Republic of Congo, links VSLAs for women with men-to-men sensitization to transform gender-inequitable norms and behaviors, and additionally combines these two project arms with an educational component about family planning and sexual and reproductive health. The project is implemented by CARE international, with the three components linked to three main objectives:

1) empowerment of women by organizing them in Village Savings and Loans Associations (VSLA). An important component of a VSLA besides the financial aspect is the development of women's capacities in organizational and financial matters, to improve self-efficacy and decision-making, and other skills. In addition, different discussion topics are developed during the cursus to further improve knowledge and skills: Human Right, Leadership, Governance, House Economics, Conflict Resolution, Family Planning, Gender Equity and Diversity.

2) Developing 'positive masculinity' by engaging men, if possible spouses of VSLA's members, towards women's rights using a peer-to-peer approach. Men should sensitize each other and organize themselves in reflection groups in order to adopt attitudes and behaviours promoting women's economic empowerment and reducing gender based violence. Sensitisation includes the following themes: identity and the concepts of gender; masculinities; the cycle of male and female socialization; the socialization of gender: acting as a man, acting like a woman; men and interpersonal violence; gender-based violence (GBV); involvement of men in the prevention of
GBV; the ten tips for a good fatherhood: sharing of work and child care within the household; fair negotiation, equity and equality; economic partnership; mutual respect and dialogue between spouses; family planning; dissemination methodology.

3) As a third component comprehensive sexuality education for young people, which includes gender and rights themes, is offered as well. The three approaches work in interaction sustaining women's empowerment in order to increase gender equity, reduce poverty and improve health at the level of households and at the level of community (Fig. 1). The evaluation of the third component is not part of this protocol.

This research aims to clarify (a) the impact of a complex intervention associating VSLA program with men's engage program on reproductive and child health indicators, and (b) to clarify the contribution of a peer-to-peer sensitization approach engaging men for more equitable gender norms as part of a complex intervention. Main outcomes include household economy, gender norms and gender-based violence, and women's confidence to participate in household- and community-decision-making processes. Reproductive and child health outcomes include child nutritional status, utilization of antenatal care services, facility-based delivery, family-planning counselling, and women's self-rated health (Fig. 1).

\section{Conceptual framework}

A framework has been developed to operationalize how "positive masculinity" in combination with women's economic empowerment impact on the economic status of the household and on health and wellbeing (Fig. 2).

Through the MaweTatu project, men are sensitized for women's rights, including sexual and reproductive health rights. Together with women participating in VSLAs they are expected to become agents of change as regards the transformation of gender norms, which will lead to more gender-equitable attitudes, joint intra-household decisionmaking, and increased economic activities and autonomy among women. It is further expected that engaging men for gender equity enhances health and wellbeing of the family, including children's nutritional status.

\section{Methods}

This research will employ a parallel mixed-method design, combining a longitudinal cohort study (Study1) with a longitudinally designed qualitative study (Study 2). Quantitative findings will be triangulated with qualitative findings in order to deepen the understanding of the forces that trigger and sustain the expected change. 


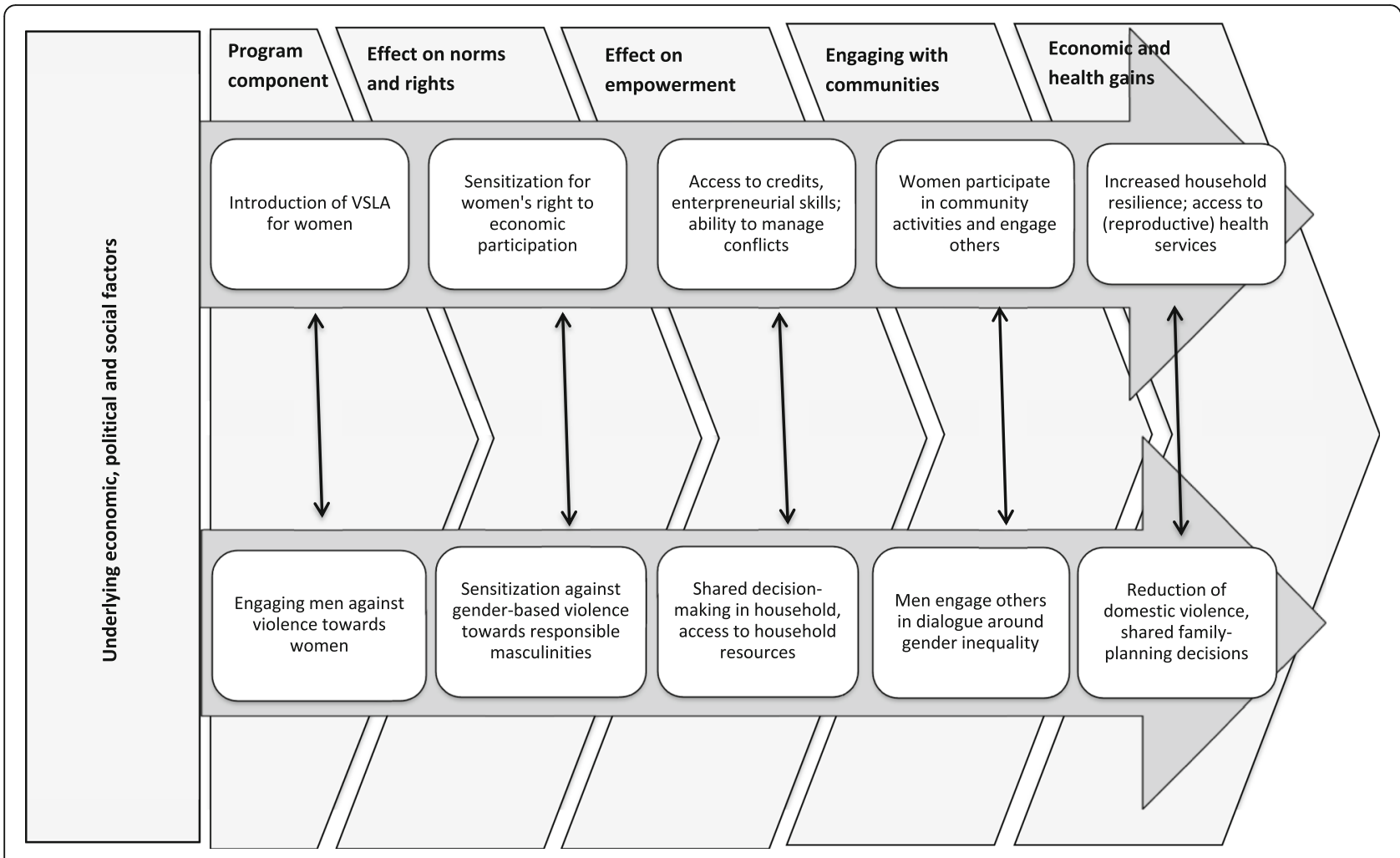

Fig. 1 Mawe tatu's Project framework

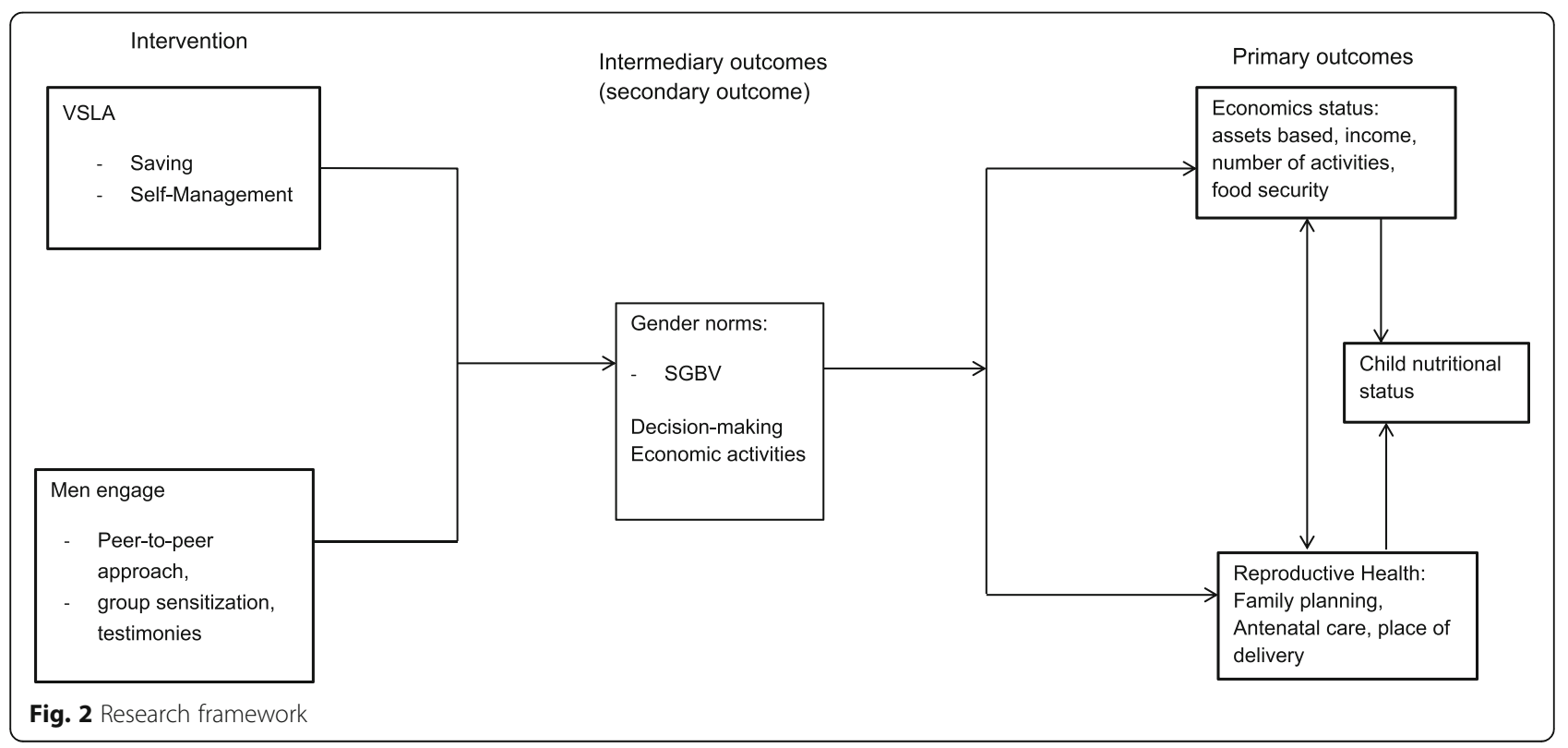




\section{Study component 1 - quantitative} Study design and study population

A cluster-randomized, longitudinal intervention study compares VSLA participants in an intervention area with controls over a period of 12 months. The intervention districts are identified a priori by the implementing organization, but the intervention and control sites (villages) are randomly selected within these districts. In the intervention sites, all persons participating in a newly created VSLA are eligible for inclusion in the intervention arm. While participation in a VSLA is based on self-selection, a random sample of VSLA participants is selected based on VSLA members' lists available from the Mawe Tatu project.

A control group of participants is recruited in adjacent randomly selected villages where VSLAs are not offered. Participants self-select to take part in an information session on income-generation or a related theme in order to recruit participants with a similar socio-economic profile as the VSLA members. A random sample of participants of the information sessions is then included in the study as controls. In both the intervention and control areas, a community leader conveys the information about the upcoming activities in a similar way in order to attract a similar group of participants.

Additional inclusion criteria for the study included being long-term residents of the study site (living in the household for at least 6 months) and being at least 15 years old. For participants with children, all children aged $1-5$ years currently living in the household of an adult study participant are recruited for inclusion in the anthropometric study module. Children included in the study must be under guardianship of the adult study participant (Table 1).

\section{Instruments}

The survey questionnaire includes questions about primary outcomes: household economy (income-generation, income, assets, housing, relative household status, health insurance), child nutritional status; and unmet need of family planning. Secondary outcome variables encompass gender norms and rights (perception of women's rights and gender equity, women's participation in decision-making and incomegeneration, women's utilization of reproductive health services, and women's perceived self-efficacy to speak out in community meetings). Further questions include information about the household structure (household composition and headship), and individual socio-demographic information (age, education, marital status, number of children), and program-related variables (participant of VSLA, time in VSLA, partner participation in men's reflection groups) (Table 2). A locally adapted composite wealth score is calculated based on structure of the house, type of fuel for cooking, toilet facility, food security, and having a mobile phone or TV. Questions from previously validated instruments are used if available (Demographic and Health Survey [7], Foodinsecurity experience scale [50], Gender-equitable Men scale [51]). Anthropometric data is collected from children under 5 years of age living in the household including weight, height and mid-upper arm circumference (MUAC). An overview over the indicators used is provided in Table 2.

\section{Sample size calculation/justification}

The power calculation is based on the hypothesis that establishing savings and loan systems at the village level lowers the risk of stunting of children up to the follow-up. Improved child growth is a result of increased livelihood and food security that is sustainable over some time. The surveys are conducted in 80 villages with an average of 15 households per village (1200 households). Assuming an attrition rate of $30 \%$ during follow-up this results in a final analytic sample size of 800 . The control group is planned to be smaller with 40 villages (600 households). Assuming the same attrition rate there must be 400 households recruited to participate in the final control arm.

As there are few data on the distribution of individual growth rates among children in the study area, we express the intervention effect in terms of a certain fraction of the standard deviation SD of individual growth rates. If the mean change in height during a given time period increases by $\mathrm{z}$ standard deviations as a consequence of the intervention, then this corresponds to a shift of the median of growth to the $\Phi(\mathrm{z})$-quantile of the distribution in the control group (where $\Phi$ denotes the cumulative density function of the standard normal distribution. For instance, if $\mathrm{z}=0.25$, this corresponds to an interventionrelated shift of the distribution whose new median is where the 60th percentile of the original distribution was.

\section{Data collection}

A team of local researchers fluent in the locally spoken languages is trained over a week in data collection methods,

Table 1 Study population by intervention and control group, quantitative study component

\begin{tabular}{lll}
\hline Study participants & Intervention group & Control group \\
\hline Women & VSLA member & $\begin{array}{l}\text { Participated in information session, } \\
\text { not member of a VSLA }\end{array}$ \\
Children (1-5 years) & $\begin{array}{l}\text { Children who are in guardianship of } \\
\text { an adult study participant member } \\
\text { of VSLA }\end{array}$ & $\begin{array}{l}\text { Children in guardianship of an } \\
\text { adult participating in control group }\end{array}$ \\
\hline
\end{tabular}


Table 2 Study variables

\begin{tabular}{|c|c|c|}
\hline Variables & Type of variable & Units \\
\hline \multicolumn{3}{|l|}{ 1. Primary outcomes } \\
\hline \multicolumn{3}{|l|}{ Household economy } \\
\hline Assets & Categorical & \\
\hline Relative household economic status & Categorical & \\
\hline Household food security & Likert scale, Qualitative data & $1-3$ \\
\hline Income-generating activities & Categorical & \\
\hline Income & continuous & \\
\hline Housing & categorical & \\
\hline Composite wealth indicator, asset based & Categorical & \\
\hline \multicolumn{3}{|l|}{ Child nutritional status } \\
\hline Weight & Continuous & $\mathrm{Kg}$ \\
\hline Height & Continuous & $\mathrm{Cm}$ \\
\hline MUAC & Continuous & $\mathrm{Mm}$ \\
\hline Weight for Height & categorical & \\
\hline Weight for age & Categorical & \\
\hline Height for age & categorical & \\
\hline \multicolumn{3}{|l|}{ Unmet need of family planning } \\
\hline Counselling and use of FP & Binary & Yes or no \\
\hline \multicolumn{3}{|l|}{ 2. Secondary outcomes } \\
\hline perception of women's rights and gender equity ${ }_{\prime \prime}$ and & Likert scale, Qualitative data & \\
\hline women's participation in decision-making and income-generation, & Likert scale, Qualitative data & \\
\hline \multicolumn{3}{|l|}{ women's utilization of reproductive health services } \\
\hline Attendance of ANC during last pregnancy & Binary Qualitative data & Yes or no \\
\hline Place of delivery of the last child & Categorical & $\begin{array}{l}\text { Hospital, health } \\
\text { care facilities, } \\
\text { home }\end{array}$ \\
\hline women's perceived self-efficacy to speak out in community meetings & Likert scale, Qualitative data & \\
\hline \multicolumn{3}{|l|}{ 3. General characteristics } \\
\hline Sex & Binary & Male/female \\
\hline Age & Continuous & Months \\
\hline Marital status of parents/tutor & Categorical & $\begin{array}{l}\text { Married, single, } \\
\text { divorced, }\end{array}$ \\
\hline Household size & Continuous & \\
\hline Sex of main breadwinner & Binary & Male/female \\
\hline \multicolumn{3}{|l|}{ 4. Program-related variables } \\
\hline Belonging to VSLA & Binary & Yes or no \\
\hline Time in VSLA & Continuous & \\
\hline Partner or husband engaged in peer-to-peer reflexion group & Binary & Yes or no \\
\hline
\end{tabular}

followed by a pilot study. Participation in the survey is voluntary and refusal to participate will have no repercussion whatsoever. The study information and consent forms are translated into local languages. Informed verbal and written consent is obtained from each individual prior to the beginning of data collection. Data will be collected strictly respecting confidentiality. No compensation will be offered in exchange for participation in the survey and no fees will be required from participants. The structured questionnaire is administrated using tablet technology and the Open Data Kit (ODK) software package. Data is stored on a secured server located at the Swiss Tropical and Public Health institute in Basel. 
Anthropometric measurements of children are taken by trained surveyors using a weighing scale, a tape measure and a (Mid-upper arm circumference) MUAC measuring tape [52].

\section{Statistical analysis plan}

An intention-to-treat analysis comparing all persons who were initially participating in a VSLA with a control group will establish the effect of participating in the project on household economies (composite wealth score; number of income-generating activities), on child nutritional status (height for age z-score HAZ, weight for age z-score WAZ, and weight for height $\mathrm{z}$-score WHZ, mid-upper-arm circumference), and on the use of family planning (current use of modern family planning method; unmet need for contraception) as the primary outcomes.

Primary outcomes Household economic status will be assessed using an asset-based wealth score and number of income-generating activities. For the analysis and validation of scaling properties of the composite wealth score principal component analysis will be used.

To measure child nutritional status, measures of chronic and acute malnutrition will be used. Stunting (small-for-age) as measure of chronic malnutrition will be measured as height for age index z-scores (HAZ): a HAZ $<-2$ SD was defined as stunted, a HAZ between $-2 \mathrm{SD}$ and $-3 \mathrm{SD}$ was defined as moderate stunting and a $\mathrm{HAZ}<-3$ z-score was defined as severe stunting. Underweight will be measured as weight for age index $\mathrm{z}$-scores (WAZ): a $\mathrm{WAZ}<-2 \mathrm{SD}$ was defined as underweight, a WAZ between $-2 \mathrm{SD}$ and $-3 \mathrm{SD}$ was defined as moderate underweight and a $W A Z<-3 S D$ was defined as severe underweight. Wasting, measuring acute malnutrition as weight for height $\mathrm{z}$-scores $(\mathrm{WHZ})<-$ $2 \mathrm{SD}$, a WHZ between - 2SD and - 3SD as moderate wasting and a $\mathrm{WHZ}<-3 \mathrm{SD}$ as severe wasting. A MUAC $<115$ $\mathrm{mm}$ will also define a severe malnutrition [52-54]. To measure food security, the FAO food insecurity experience scale is used [50]. Family planning use is measured as proportion of women currently using modern contraceptives, and as unmet need for family planning.

Secondary outcomes In addition to the primary outcomes, secondary outcomes include changing gender norms (attitudes towards women's rights, gender-based violence, women's roles) and women's empowerment (participation in the economy; self-efficacy to express their views; intra-household decision-making; use of health services; gender-based violence). (Table 3).

First, descriptive statistics will be calculated for the primary and secondary outcome variables, and for socioeconomic characteristics. Assets, number of incomegenerating strategies, food security and child nutritional status, use of family planning and other reproductive
Table 3 Power calculations for child anthropometric data

\begin{tabular}{|c|c|c|c|c|c|}
\hline $\begin{array}{l}\text { Effect } \\
\text { size }\end{array}$ & $\begin{array}{l}\text { Shift of } \\
\text { median } \\
\text { to }\end{array}$ & $\mathrm{ICC}^{\mathrm{a}}$ & $\begin{array}{l}\text { SD of } \\
\text { random } \\
\text { village } \\
\text { effect }\end{array}$ & $\begin{array}{l}\text { Child in every HH } \\
\text { Power }\end{array}$ & $\begin{array}{l}\text { Child in } 50 \% \mathrm{HH} \\
\text { Power }\end{array}$ \\
\hline \multirow[t]{6}{*}{$0.27 \mathrm{SD}$} & \multirow[t]{6}{*}{ P61 } & 0.01 & $0.1 \mathrm{SD}$ & $99 \%$ & $86 \%$ \\
\hline & & 0.02 & 0.14 SD & $98 \%$ & $84 \%$ \\
\hline & & 0.03 & 0.18 SD & $97 \%$ & $83 \%$ \\
\hline & & 0.04 & 0.21 SD & $96 \%$ & $81 \%$ \\
\hline & & 0.05 & 0.23 SD & $95 \%$ & $79 \%$ \\
\hline & & 0.10 & 0.33 SD & $86 \%$ & - \\
\hline \multirow[t]{6}{*}{0.25 SD } & \multirow[t]{6}{*}{ P60 } & 0.01 & $0.1 S D$ & $97 \%$ & $80 \%$ \\
\hline & & 0.02 & 0.14 SD & $96 \%$ & $78 \%$ \\
\hline & & 0.03 & 0.18 SD & $95 \%$ & $77 \%$ \\
\hline & & 0.04 & $0.21 \mathrm{SD}$ & $93 \%$ & $75 \%$ \\
\hline & & 0.05 & 0.23 SD & $91 \%$ & $73 \%$ \\
\hline & & 0.10 & 0.33 SD & $80 \%$ & - \\
\hline \multirow[t]{5}{*}{0.2 SD } & \multirow[t]{5}{*}{ P58 } & 0.01 & $0.1 S D$ & $88 \%$ & - \\
\hline & & 0.02 & 0.14 SD & $84 \%$ & - \\
\hline & & 0.03 & 0.18 SD & $81 \%$ & - \\
\hline & & 0.04 & $0.21 S D$ & $78 \%$ & - \\
\hline & & 0.05 & $0.23 \mathrm{SD}$ & $75 \%$ & - \\
\hline
\end{tabular}

Table 3 gives the achievable power for different effect sizes and intra class correlation coefficients. The expected power is given both under the

assumption that a) a child under 5 years old will be found in each household, and b) that a child under 5 years old is found only in every other household. Intra-class coefficients reported in other African contexts range from 0.01 to 0.05

$S D$ standard deviation of individual growth rates

aproportion of variance explained by the factor village

health services, and related knowledge, and prevalence of perceptions of gender relations (beliefs and attitudes), and prevalence of different levels of knowledge on sexual and reproductive health including use of family planning methods and existing services will be documented. For this purpose, percentages, means and standard deviations will be computed. To assess self-efficacy and decision-making power, indices will be built using Mokken analysis, which is a nonparametric procedure based on item-response theory that has been used to assess similar scales in previous studies [55, 56]. Differences between education level, rural and urban populations will be assessed statistically using Chi2 tests for different degrees of freedom for categorical variables, or using ttests for continuous variables.

To assess the program effects, mixed-effect regression models will be run for each primary outcome variable to establish change in the outcome variables over time (baseline to endline) and by intervention and control group. The models will be adjusted for socio-economic confounders, and clustering will be considered at the level of villages. The same analysis as for primary outcomes will be conducted for secondary outcomes. In addition, the 
role of mediating factors will be investigated. It will be explored whether a change in the power of decision-making mediates changes in household economic status and use of family planning (FP). In addition, we will study whether children's nutritional status improves if men are supportive of women's economic activities. For this purpose structural equation modelling (SEM) with maximum likelihood estimation will be conducted to investigate the complex and multidimensional pathways by which the association of a positive masculinity and women's empowerment directly or indirectly affect household economics status, children nutritional's status and use of reproductive health services, and the potential role of mediating variables.

Results will be discussed under consideration of the fidelity of the intervention. Women who complete the full cycle of a VSLA and men who participate in the full cursus of the peer-to-peer sensitisation group will determine the level of fidelity.

Analysis will be conducted with STATA V.15.

\section{Study 2 - qualitative component}

A qualitative study with households participating in a VSLA will be conducted, collecting data on gender relations, women's economic participation and access to sexual and reproductive health services.

\section{Study design}

Qualitative studies are by nature smaller and capable of providing in-depth insights into processes within selected households and couples of a particular study site [57].

With the qualitative study, women and their partners are closely followed through multiple interviews, including collection of information related to their income and expenditure, as well as information on gender-based dynamics within families and communities. Health-related behaviour and perceptions of family planning will also be explored in the context of men engaged and women's empowerment to assess a change in behaviours and perceptions after men's sensitization as well motivations for the change.

\section{Instruments}

For the qualitative interviews a guide is developed focusing on the impact participation in the project has on women's families in terms of gender-relations, household economy, and health. Over time, the instrument is adapted based on the results from previous interviews to capture emerging themes. Focus group discussions (FGD) with 6-8 participants, with women and men separately will be organized as well as individual in-depth interviews (IDIs). We will use purposive sampling to recruit 18-49 years old women participating in VSLA whose husbands are also participating in either VSLA or a reflection group. Two focus groups will be organized with the same participants after a one-year interval. We plan to do five to seven FGDs coupled with IDIs carried out with same participants as FGD.

\section{Study population and sampling}

Participants of the qualitative study are recruited from households where both partners are involved in the intervention: women participating in VSLA and their partner participating in a male reflection group. Women and men in qualitative are recruited in the same villages but are not part of the quantitative study. We plan to conduct $20-30$ in depth interviews with women and men or until saturation is reached [58]. Different themes such as gender norms, roles and justice in society, communication between husband and wives, and gendered responsibility in health and in households' economics will be explored. Observations of women in VSLAs and at their home during the visits will be done throughout the process. Attitudes, the ability to feel confident to speak about anything related to women's health and the nutrition of children with special regards on the involvement of men will be collected.

\section{Data collection}

Interview guides will be developed to explore dynamics of participating in VSLA and men's sensitization for traditional roles and decision making at the level of the household with a specific focus on gender, household economy, and maternal and children health. Interviews will be carried out by a researcher familiar with the local setting and language. Interviews will be conducted in Kiswahili after written informed consent is obtained. No compensation will be offered in exchange for participation in the study. Interviews will be conducted in a isolated place chosen by the participant either in their home or outside. The researcher will make sure that privacy and confidentiality is always granted. The narratives from qualitative data collection will be voice-recorded and transcribed in Swahili. Observations will also be done during VSLA discussion sessions; notes will be taken and transcribed in French language. VSLA discussions on health topics relevant to this study will eventuality be targeted and recorded for analysis. Observations of women in VSLAs and at their home during the visit will be conducted; notes will be taken and transcribed in French.

\section{Data analysis plan}

Coding will be done with the help of qualitative data analysis software (Atlas TI). Latent themes will be identified by inductive analysis, reading and re-reading transcripts as well as notes from observations. At every round of iterative analysis emergent codes will be compared, grouped and contextualized. Finally, using a hermeneutic approach, the emerging hypotheses will be integrated in a wider contextual analysis. 


\section{Quantitative and qualitative: data triangulation}

Quantitative data will provide associations between outcomes and different factors in the study. Throughout the analysis, qualitative and quantitative results will be discussed in the study team, and triangulation will be done between qualitative and quantitative results (convergent parallel design). The qualitative analysis will shed light on aspects that cannot easily be quantified. Qualitative research is needed in order to understand why people give a specific answer especially for sensitive topics like gender, power and decision-making as those are strongly linked to social norms and individuals perceptions. It will also help to generate hypotheses on how to construct the structural equation models during the quantitative analysis.

\section{Discussion}

Women's empowerment can bring about change in various areas, including health $[8,43,59]$. Nevertheless, it has been argued that this is not enough. It has been shown that men's commitment to gender equity is an indispensable prerequisite for better results, especially in terms of reproductive health and child nutrition. This study of a complex intervention will attempt to verify the combination of the two: women's empowerment on one side and peer-to peer sensitization among men on the other side. Following participants longitudinally will yield a comprehensive understanding of the effect of positive masculinity on the use of reproductive health services and the nutrition of children, and on gender-power dynamics at the household and community levels.

This study, the first of its kind in the region investigating the impact of men's involvement on women's health and child nutrition could serve as basis for further research, in particular to explore the impact of men's involvement on maternal and infant morbidity and mortality. Results will also help to define how best to improve engaging men in the transformation of social and gender norms and hopefully to define new strategies for improving maternal and child health through community-based, participatory interventions. This study will serve as a guide for policies aimed at improving the involvement of men to improve women's health by increasing the use of maternal health services (antenatal care, family planning, maternity) and to reduce children's malnutrition.

\begin{abstract}
Abbreviations
ANC: AnteNatal Care; DRC: Democratic Republic of Congo; EDS: Enquête Démographique de Santé; EKNZ: Ethic Kommission Nord-und Zentralschweiz; FGD: Focus Group Discussion; HAZ: Height for Age (stunting); IDIs: In-depth Interviews; MUAC: Mid up arm circumference; NGO: Non-governmental organization; SEM: Structural Equation Modeling; UNDP: United Nations Development and Population; VSLA: Villages save loans associations; WHO: World Health Organization; WHZ: Weight for Height (wasting)
\end{abstract}

\section{Acknowledgements}

We acknowledge the research chair principal investigator and funding sources supporting this study. We thank all experts who have contributed to this study. Special thanks to Joelle Schwarz, Mari Dumbaugh, Elizabeth Zemp and Jana Gerold who review critically the proposal for important intellectual content and to Christian Schindler who lead statistical aspects (sample size calculation, randomisation procedure and statistical analysis). Thanks to all participants who kindly agree to answer us. We acknowledge and an extend of gratitude towards all fieldworkers and CARE DRC staff, Tarcile Kashale and all the team who persevere and will make the data collection a success for the outcomes of this study.

\section{Authors' contributions}

SM and WBA were involved in conception, writing the study protocol, formulating the study, training for data collectors, supervising data collection process and drafting the manuscript. GFF was involved in writing the protocol and drafting the manuscript. CB, JM, LKT, GB were involved in drafting the manuscript. All authors have read and approved the final version of the protocol paper.

\section{Funding}

The main partners will be the international non-governmental agent (NGO) implementing the Mawe tatu project, where CARE Nederland is the contract holder and CARE DRC the main implementing organisation, in collaboration with two local partner organisations. Mawe tatu is financed by the Dutch Embassies regional Great Lakes programme. CARE DRC, local NGO partners of Mawe tatu will be implementing the approach in DRC. The grant is managed by CARE; Swiss TPH participated as a partner organisation in the initial application and was then subcontracted by CARE. The researchers will be working closely with Mawe tatu staff in North and South Kivu/DRC for information and insight on research context including security, access to local authorities, key informants, and transport to and from research sites among other logistical issues. The funder was not involved in the study design, data collection, analysis and interpretation.

\section{Availability of data and materials}

Dataset generated and/or analysed are not publicly available due to confidentiality and anonymity of study population. Datasets are stored on a secure Alfresco website and are available from the corresponding author on reasonable request.

\section{Ethics approval and consent to participate}

This protocol is nested in an impact evaluation 'Linking Village Saving and Loan associations with gender-transformative approaches for reproductive health: Evaluation of the 'Mawe Tatu' project in North and South Kivu, DRC' and focused on men's involvement in gender transformative strategies and the strategy's subsequent impact on health.

The main research proposal was approved in 2016 by the EKNZ Ethical committee (Ethik Kommission Nord-und Zentralschweiz N ${ }^{\circ}$ EKNZ BASEC UBE 2016-01878) in Switzerland and by the Ethics Committee of the Catholic University of Bukavu in Democratic Republic of Congo (N UCB/CIE/NC/019/2016). Informed verbal and written consent will be obtained from each individual prior to the beginning of data collection and all consent forms are translated into local languages. Confidentiality is guaranteed and data are saved anonymously.

\section{Consent for publication}

Not applicable.

\section{Competing interests}

The authors declare that they have no competing interests.

\section{Author details}

${ }^{1}$ Swiss Tropical and Public Health Institute, Basel, Switzerland. ${ }^{2}$ University of Basel, Basel, Switzerland. '3niversité Catholique de Bukavu, Bukavu, Democratic Republic of the Congo. ${ }^{4}$ CARE International DRC, Kinshasa, Democratic Republic of the Congo. ${ }^{5}$ CARE Nederland, The Hague, Netherlands.

Received: 17 May 2019 Accepted: 15 December 2019

Published online: 14 January 2020

References

1. WHO Media center. Children: reducing mortality. Geneva: WHO; 2016. 
2. Black RE, Allen LH, Bhutta ZA, Caulfield LE, Md O, Ezzati M, Mathers C, Rivera J. Maternal and child undernutrition: global and regional exposures and health consequences. Lancet. 2008;371(9608):243-60.

3. Klasen S. Poverty, undernutrition, and child mortality: some inter-regional puzzles and their implicationsfor research and policy. J Econ Inequal. 2008;6(1):89-115.

4. United Nations Development Program, World Health Organization. United Nations Millennium Development Goals. Accessed 9 May 2018.

5. United Nations Development Program: A propos de la RDC. Le PNUD en République démocratique du Congo Accessed 9 May 2018.

6. World Health Organization: Maternal mortality country profiles. Accessed 9 May 2018

7. Ministère du Plan et Suivi de la Mise en oeuvre de la Révolution de la Modernité (MPSMRM), Ministère de la Santé Publique (MSP) et ICF International. Enquête Démographique et de Santé en République Démocratique du Congo 2013-2014: Rapport de synthèse. Rockville: MPSMRM, MSP et ICF International; 2014.

8. Duflo E. Women empowerment and economic development. J Econ Lit. 2012;50(4):1051-79.

9. Dumbaugh M, Bapolisi W, Bisimwa G, Mwamini MC, Mommers P, Merten S. Navigating fertility, reproduction and modern contraception in the fragile context of south Kivu, Democratic Republic of Congo: 'Les enfants sont Une richesse'. Cult Health Sex. 2019;21(3):323-37.

10. Manda-Taylor L, Mwale D, Phiri T, Walsh A, Matthews A, Brugha R, Mwapasa V, Byrne E. Changing times? Gender roles and relationships in maternal, newborn and child health in Malawi. BMC Pregnancy Childbirth. 2017;17(1):321.

11. Abdullah YS, Duasa J. Household decision-making and expenditure patterns of married men and women in Malaysia. J Fam Econ Iss. 2010;31(3):371-81.

12. Akombi BJ, Agho KE, Hall JJ, Wali N, Renzaho AM, Merom D. Stunting, wasting and underweight in Sub-Saharan Africa: A systematic review. Int J Environ Res Public Health. 2017;14(8):863.

13. Alaofè H, Zhu M, Burney J, Naylor R, Douglas T. Association between women's empowerment and maternal and child nutrition in Kalalé District of northern Benin. Food Nutr Bull. 2017;38(3):302-18.

14. Keino S, Plasqui G, Ettyang G, van den Borne B. Determinants of stunting and overweight among young children and adolescents in sub-Saharan Africa. Food Nutr Bull. 2014;35(2):167-78.

15. Kabagenyi A, Jennings L, Reid A, Nalwadda G, Ntozi J, Atuyambe L. Barriers to male involvement in contraceptive uptake and reproductive health services: a qualitative study of men and women's perceptions in two rural districts in Uganda. Reprod Health. 2014;11:21.

16. Kabagenyi A, Reid A, Ntozi J, Atuyambe L. Socio-cultural inhibitors to use of modern contraceptive techniques in rural Uganda: a qualitative study. Pan Afr Med J. 2016;25:78.

17. Tilahun T, Coene G, Temmerman M, Degomme O. Spousal discordance on fertility preference and its effect on contraceptive practice among married couples in Jimma zone, Ethiopia. Reprod Health. 2014;11:27.

18. Tilahun $\mathrm{T}$, Coene G, Temmerman M, Degomme O. Couple based family planning education: changes in male involvement and contraceptive use among married couples in Jimma zone, Ethiopia. BMC Public Health. 2015;15:682.

19. Dumbaugh M, Tawiah-Agyemang C, Manu A, ten Asbroek GH, Kirkwood B, Hill Z. Perceptions of, attitudes towards and barriers to male involvement in newborn care in rural Ghana, West Africa: a qualitative analysis. BMC Pregnancy Childbirth. 2014;14:269.

20. Sternberg P, Hubley J. Evaluating men's involvement as a strategy in sexual and reproductive health promotion. Health Promot Int. 2004;19(3):389-96.

21. Abate KH, Belachew T. Women's autonomy and men's involvement in child care and feeding as predictors of infant and young child anthropometric indices in coffee farming households of Jimma zone, South West of Ethiopia. PLOS One. 2017;12(3):e0172885.

22. Barker G, Ricardo C, Nascimento M, Olukoya A, Santos C. Questioning gender norms with men to improve health outcomes: evidence of impact. Global Public Health. 2010;5(5):539-53.

23. Bich T. Relationship between paternal involvement and child malnutrition in a rural area of Vietnam. Food Nutr Bull. 2008;29:59-66.

24. Madhavan S, Townsend N. The social context of children's nutritional status in rural South Africa. Scand J Public Health. 2007;69:107-17.

25. Rahman A. Women's empowerment: Concept and beyond. Glob J Inc. 2013; 13(6):8-13

26. Abramsky T, Lees S, Stöckl H, Harvey S, Kapinga I, Ranganathan M, Mshana $G$, Kapiga S. Women's income and risk of intimate partner violence: secondary findings from the MAISHA cluster randomised trial in NorthWestern Tanzania. BMC Public Health. 2019;19:1108.
27. Raj A, Silverman JG, Klugman J, Saggurti N, Donta B, Shakya HB. Longitudinal analysis of the impact of economic empowerment on risk for intimate partner violence among married women in rural Maharashtra, India. Soc Sci Med (1982). 2018;196:197-203.

28. Schuler SR, Nazneen S. Does intimate partner violence decline as women's empowerment becomes normative? Perspectives of Bangladeshi women. World Dev. 2018;101:284-92.

29. Falb KL, Annan J, King E, Hopkins J, Kpebo D, Gupta J. Gender norms, poverty and armed conflict in Côte D'lvoire: engaging men in women's social and economic empowerment programming. Health Educ Res. 2014;29(6):1015-27.

30. Hossain M, Zimmerman C, Kiss L, Watts C: Violence against women and men in Côte d'Ivoire: A cluster randomized controlled trial to assess the impact of the 'Men and Women in Partnership' intervention on the reduction of violence against women and girls in rural Côte d'Ivoire Formative results from a community survey. London: London School of Hygiene \& Tropical Medicine (LSHTM) and The International Rescue Committee (IRC); 2010.

31. Gupta J, Falb KL, Lehmann H, Kpebo D, Xuan Z, Hossain M, Zimmerman C, Watts C, Annan J. Gender norms and economic empowerment intervention to reduce intimate partner violence against women in rural cote d'Ivoire: a randomized controlled pilot study. BMC Int Health Hum Rights. 2013;13:46.

32. McDonagh A. Microfinance strategies for HIV/AIDS mitigation and prevention in sub- Saharan Africa. International Lobour Organization; 2001. http://www.ilo.org/public/libdoc/ilo/2001/101B09_344_engl.pdf.

33. Kelly M, Dunford B, Davis C. Impact of credit with education on mothers and their young children's nutrition: CRECER credit with education program in Bolivia. Freedom Hunger. 1999:5:122.

34. Reiter B, Peprah J. Microfinance in Ghana: an exploratory case study. Br J Educ Soc Behav Sci. 2014;5:433-49.

35. Van Rooyen C, Stewart R, de Wet T. The impact of microfinance in sub-Saharan Africa: a systematic review of the evidence. World Dev. 2012;40(11):2249-62.

36. MacPherson E, Sadalaki J, Nyongopa V, Nkhwazi L, Phiri M, Chimphonda A, Desmond N, Mwapasa V, Lalloo DG, Seeley J, et al. Exploring the complexity of microfinance and HIV in fishing communities on the shores of Lake Malawi. Rev Afr Polit Econ. 2015;42(145):414-36.

37. Annan J, Bundervoet T, Seban J, Costigan J. A randomized impact evaluation of village savings and loans associations and family-based interventions in Burundi: International Rescue Committee, USAID; 2013. https://pdfs. semanticscholar.org/1108/8c32d5b9d0afdbf21eb20701075030acf3d3.pdf.

38. Gibbs A, Willan S, Misselhorn A, Mangoma J. Combined structural interventions for gender equality and livelihood security: a critical review of the evidence from southern and eastern Africa and the implications for young people. J Int AIDS Soc. 2012;15(Suppl 1):1-10.

39. Oxfam. Saving for Change: Financial inclusion and resilience for the world's poorest people: Oxfam; 2013. https://www.oxfamamerica.org/static/oa4/ oxfam-america-sfc-ipa-bara-toplines.pdf.

40. Zakaras JM, Weiser SD, Hatcher AM, Weke E, Burger RL, Cohen CR, Bukusi EA, Dworkin SL. A qualitative investigation of the impact of a livelihood intervention on gendered power and sexual risk behaviors among hivpositive adults in rural Kenya. Arch Sexual Behav. 2016;46(4):1121-33.

41. Mersland R, Eggen $\varnothing$. In: NORAD, editor. You cannot save alone - financial and social mobilization in Savings \& Credit Groups; 2007.

42. Brunie A, Fumagalli L, Martin T, Field S, Rutherford D. Can village savings and loan groups be a potential tool in the malnutrition fight? Mixed method findings from Mozambique. Child Youth Serv Rev. 2014;47:113-20.

43. Kim JC, Watts CH, Hargreaves JR, Ndhlovu LX, Phetla G, Morison LA, Busza J, Porter JDH, Pronyk P. Understanding the impact of a microfinance-based intervention on women's empowerment and the reduction of intimate partner violence in South Africa. Am J Public Health. 2007;97(10):1794-802.

44. Bass J, Murray S, Cole G, Bolton P, Poulton C, Robinette K, Seban J, Falb K, Annan J. Economic, social and mental health impacts of an economic intervention for female sexual violence survivors in eastern Democratic Republic of Congo. Glob Ment Health (Camb). 2016;3:e19.

45. Surmont T. Analyzing Village Savings and Loans Associations through the Sustainable Livelihoods Approach. A case study in Kabarole district. Ghent: University of Ghent; 2017.

46. Barker G, Ricardo C, Nascimento M. Engaging men and boys in changing gender-based inequity in health: evidence from programme interventions, vol. 76. Geneva: WHO; 2007.

47. Promundo, salud C, REMADES. Program P, a Manual for Engaging Men in Fatherhood, Caregiving and Maternal and Child Health. MenCare. 2013. 
48. Abramsky T, Devries KM, Michau L, Nakuti J, Musuya T, Kyegombe N, Watts C. The impact of SASA!, a community mobilisation intervention, on women's experiences of intimate partner violence: secondary findings from a cluster randomised trial in Kampala, Uganda. J Epidemiol Community Health. 2016;70(8):818-25.

49. Casey E, Carlson J, Two Bulls S, Yager A. Gender transformative approaches to engaging men in gender-based violence prevention: a review and conceptual model. Trauma, Violence Abuse. 2018;19(2):231-46.

50. Cafiero C, Viviani S, Nord M. Food security measurement in a global context: the food insecurity experience scale. Measurement. 2018;116:146-52.

51. Nanda G. Compendium of Gender Scales. In; Edited by 360/C-Change F. Washington, DC: USAID; 2011.

52. World Health Organization. Anthropometric reference data for international use. Geneva: WHO; 2007.

53. World Health Organization: Nutrition Landscape Information System (NLIS) country profile indicators: interpretation guide. 2010. [https:/apps.who.int/ iris/handle/10665/44397]

54. World Health Organization, United Nations Children's Fund. WHO child growth standards and the identification of severe acute malnutrition in infants and children. A Joint Statement. Geneva: WHO; 2009.

55. Gari S, Malungo JR, Martin-Hilber A, Musheke M, Schindler C, Merten S. HIV testing and tolerance to gender based violence: a cross-sectional study in Zambia. PLoS One. 2013;8(8):e71922.

56. Stochl J, Jones PB, Croudace TJ. Mokken scale analysis of mental health and wellbeing questionnaire item responses: a non-parametric IRT method in empirical research for applied health researchers. BMC Med Res Methodol. 2012;12:74.

57. Luborsky MR, Rubinstein RL. Sampling in qualitative research. Res Aging. 1995;17(1):89-113.

58. Creswell JW. Qualitative inquiry and research design: choosing among five traditions. London: Sage publications; 1998.

59. Mandal M, Muralidharan A, Pappa S. A review of measures of women's empowerment and related gender constructs in family planning and maternal health program evaluations in low- and middle-income countries. BMC Pregnancy Childbirth. 2017;17(Suppl 2):342.

\section{Publisher's Note}

Springer Nature remains neutral with regard to jurisdictional claims in published maps and institutional affiliations.

Ready to submit your research? Choose BMC and benefit from:

- fast, convenient online submission

- thorough peer review by experienced researchers in your field

- rapid publication on acceptance

- support for research data, including large and complex data types

- gold Open Access which fosters wider collaboration and increased citations

- maximum visibility for your research: over $100 \mathrm{M}$ website views per year

At $\mathrm{BMC}$, research is always in progress.

Learn more biomedcentral.com/submissions 